\title{
Aldo-Keto Reductase Family 1 Member C3
}

National Cancer Institute

\section{Source}

National Cancer Institute. Aldo-Keto Reductase Family 1 Member C3. NCI Thesaurus. Code C129054.

Aldo-keto reductase family 1 member C3 (323 aa, $37 \mathrm{kDa}$ ) is encoded by the human AKR1C3 gene. This protein is involved in steroid and prostaglandin metabolism. 